\title{
Synovial Sarcoma with Neuronal Differentiation- A Case Report
}

\author{
Dr. Balaji $\mathrm{S}^{1^{*}}$, Dr. Jonathan Arnold ${ }^{2}$, Dr. Govindaraj $\mathrm{T}^{3}$, Dr. Muthukumar ${ }^{4}$
}

\author{
${ }^{1}$ Post Graduate Department of Pathology, Sri Venkateshwaraa Medical College and Research Centre, 13-A, Pondy-Villupuram Main \\ Road, Ariyur, Puducherry-605 102, Puducherry, 605107, India \\ ${ }^{2}$ Associate Professor Department of Pathology, Sri Venkateshwaraa Medical College and Research Centre, 13-A, Pondy-Villupuram \\ Main Road, Ariyur, Puducherry-605 102, Puducherry, 605107, India \\ ${ }^{3}$ Professor and HOD Department of Pathology, Sri Venkateshwaraa Medical College and Research Centre, 13-A, Pondy-Villupuram \\ Main Road, Ariyur, Puducherry-605 102, Puducherry, 605107, India \\ ${ }^{4}$ Professor Department of General Surgery, Sri Venkateshwaraa Medical College and Research Centre, 13-A, Pondy-Villupuram Main \\ Road, Ariyur, Puducherry-605 102, Puducherry, 605107, India
}

DOI: $10.36347 /$ sjmcr.2021.v09i03.007

| Received: 24.02.2021 | Accepted: 08.03.2021 | Published: 10.03.2021

*Corresponding author: Dr. Balaji S

\section{Abstract}

Synovial sarcomas are malignant, high-grade, soft-tissue neoplasms that are estimated to represent between $5 \%$ and $10 \%$ of all soft-tissue sarcomas. In fact, in adults, synovial sarcoma is the fourth most common type of sarcoma after malignant fibrous histiocytoma, liposarcoma and rhabdomyosarcoma. It predominantly affect the extremities but can occur in any part of the body, including the head and neck. This tumor is most prevalent in adolescents and adults between 15 and 40 years of age. Concerning gender incidence, the male: female ratio is 1.2:1, with males being more frequently affected. Synovial sarcomas not only are locally aggressive but also have a higher metastatic potential than most other soft-tissue sarcomas. Hence, the overall prognosis for synovial sarcoma patients is poor. We reported a case of synovial sarcoma with neuronal differentiation located on the dorsal aspect of the right foot of an 38 years old male. This case illustrates the neuronal differentiation of the tumor which could have been misdiagnosed as neuronal tumor in FNAC and the challenges to differentiate it from other biphasic tumors. Thorough HPE examination and immunohistochemistry are mandatory for early diagnosis and to avoid misdiagnosis.

Keywords: Undifferentiated sarcomas, synovial sarcoma, neuronal differentiation, sarcoma synovium.

Copyright $(02021$ The Author(s): This is an open-access article distributed under the terms of the Creative Commons Attribution 4.0 International License (CC BY-NC 4.0) which permits unrestricted use, distribution, and reproduction in any medium for non-commercial use provided the original author and source are credited.

\section{INTRODUCTION}

Synovial sarcomas account for approximately $7 \%$ to $10 \%$ of all human soft tissue sarcomas and predominantly affect the extremities but can occur in any part of the body, including the head and neck [1,2]. Despite its name, it arises from tissues other than normal synovial lining. Ultrastructural studies of epithelium-like cells in biphasic synovial sarcomas revealed characteristics of a true glandular epithelium, which were not observed in either superficial or deeper cells of synovium [3]. Further, immunohistochemical studies have demonstrated keratins and epithelial membrane antigen-positive epithelium-like cells in biphasic synovial sarcomas and unlike those found in the lining cells of synovium [4]. Therefore, the name "synovial sarcoma" is believed inappropriate for this class of tumor, and the cell of origin is still unknown.

\section{Case Report}

We received an excised mass from dorsal aspect of right foot of a 38 years old male with provisional diagnosis of neuronal tumor based on FNAC with brief note on MRI and CT report we further proceeded with histopathological examination.

\section{MRI RIGHT FOOT}

Large multilobulated lesion with few small cystic areas and areas of hemorrhage noted over the dorsal aspect of the foot which was suggestive of neoplastic etiology.

\section{CT AORTOGRAM}

A large well defined homogenous iso-dense mass with high internal and peripheral vascularity in the left para vertebral/superior mediastinum noted. 
Multiple similar density lesions were seen in bilateral lung fields. Right ventricle showed tumor thrombus. Overall suggestive of superior mediastinal mass lesion with metastasis.

\section{FNAC}

Highly cellular and showed benign spindle cells arranged in tightly cohesive clusters in a fibrillar background. The individual cells were spindle shaped with moderate amount of cytoplasm with elongated nuclei, some of which were bent. Also seen were cells with moderate nuclear pleomorphism and bland nuclear chromatin with presence of nuclear vacuoles (degenerative changes). The background showed numerous cyst macrophages in eosinophilic proteinaceous fluid mixed with hemorrhage. No necrosis or increase in number of mitosis were seen in the smears studied.

FNA from right foot swelling was reported as Benign spindle cell neoplasm with nuclear degeneration, probably of neural origin.

\section{GROSS EXAMINATION}

Showed a single globular soft tissue mass measuring $4 \times 3 \times 1.5 \mathrm{~cm}$. External surface irregular. Cut surface is grey brown to grey white in color, soft to firm in consistency.

\section{MICROSCOPIC EXAMINATION}

Section studied from both tissue fragments shows a neoplasm composed of cells arranged as nodules, large aggregates and islands separated by broad areas of fibro collagenous stroma. Within the tumor islands, some cells are round to oval, epithelioid with indistinct cell membrane, moderate eosinophilic cytoplasm, vesicular large nuclei with open chromatin, some of which show optical clearing with crowding of nuclei. Other cells have spindle morphology with oval to elongated vesicular predominantly uniform nuclei, \& some with wavy nuclei and arranged as short fascicles, bundles and focal vague storiform arrangement. Tumor cells show moderate atypia and hyperchromasia. There are cystic spaces in which groups, trabeculae of tumor cells are separated by irregular vascular sinusoid like spaces filled with RBCs. Some cells shows intracytoplasmic vacuoles with RBC's. Also in some areas tumor cells are arranged as aggregates lining the fibrous tissue. Some of the cells are multinucleated.

Some nodules have round cell morphology with high $\mathrm{N}: \mathrm{C}$ ratio. Mitosis in the tumor cells are1020/10 HPF and includes atypical mitosis also. Also seen are aggregates of foamy histiocytes, lymphocytes, neutrophils, eosinophils, plasma cells, mast cells, apoptotic bodies, cholesterol clefts, patches of necrosis and extensive hemorrhage along with scattered small blood vessels and dystrophic calcification, within and around tumor clusters. Tumor infiltrates adipose tissue and surrounds large vessels. No evidence of vascular or skeletal muscle invasion.

FNCLCC grading of soft tissue sarcoma: Grade 3 [total score 6]

(Differentiation-score3 [sarcoma of unknown/ doubtful type]; Mitosis -Score 2[10-19 mitosis/10HPF]; Tumor necrosis - Score $1[<50 \%$ necrosis $]$ )

\section{DIFFERENTIAL DIAGNOSIS BASED ON HISTOPATHOLOGY:}

Angiosarcoma (Epithelioid), Epithelioid sarcoma, Biphasic Synovial sarcoma \& Undifferentiated pleomorphic sarcoma

\section{IMMUNOHISTOCHEMISTRY}

\begin{tabular}{|l|l|}
\hline \multicolumn{1}{|c|}{ STAIN } & \multicolumn{1}{c|}{ RESULT } \\
\hline TLE-1 & Strong nuclear positivity \\
\hline ERG & Negative \\
\hline FLI-1 & Scattered nuclear positivity \\
\hline VIMENTIN & Strong cytoplasmic positivity \\
\hline S-100 & Positive \\
\hline
\end{tabular}




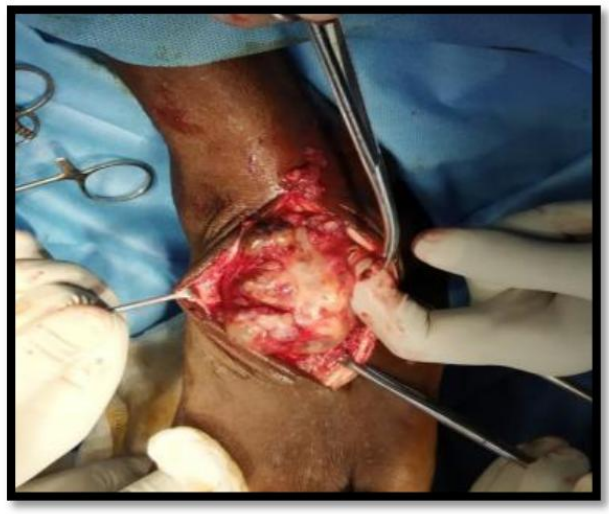

(A) INTRA OPERTIVE GROSS

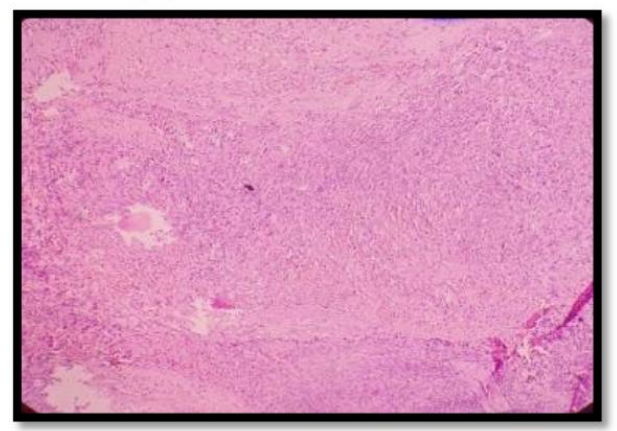

(C) SPINDLE CELLS (10X)

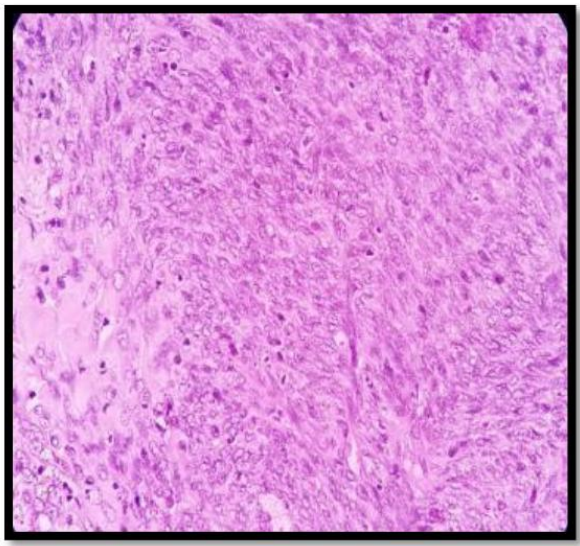

(E) SPINDLE CELLS (40X)

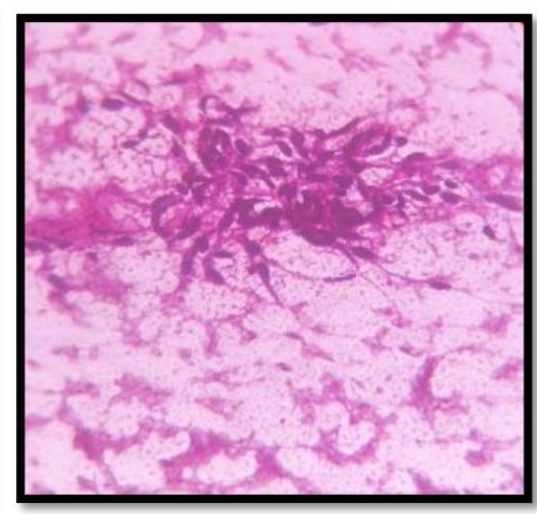

(B) FNAC- SPINDLE CELLS

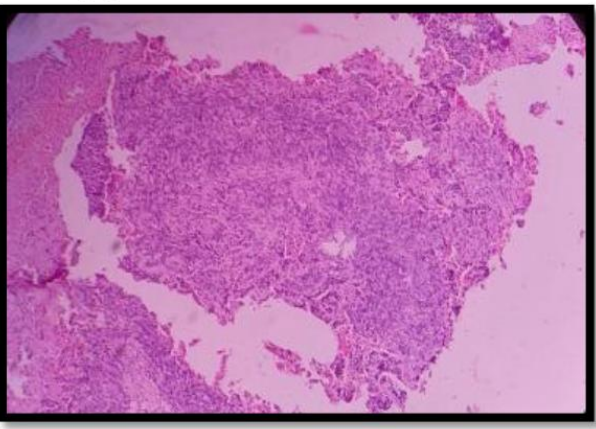

(D) EPITHELOID CELLS (10X)

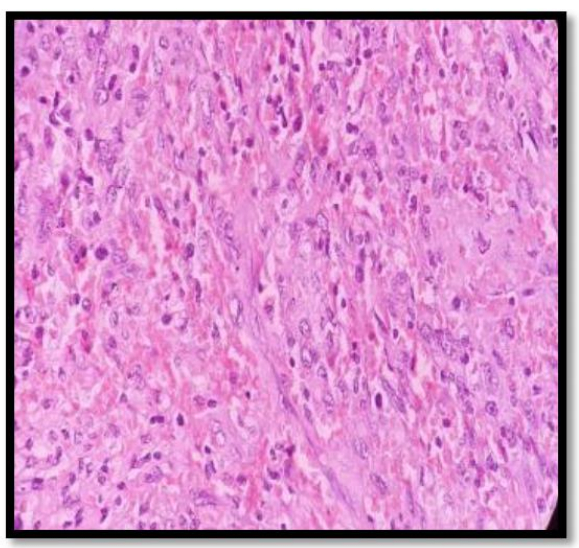

(F) VASCULAR SINUSES FILLED WITH RBC

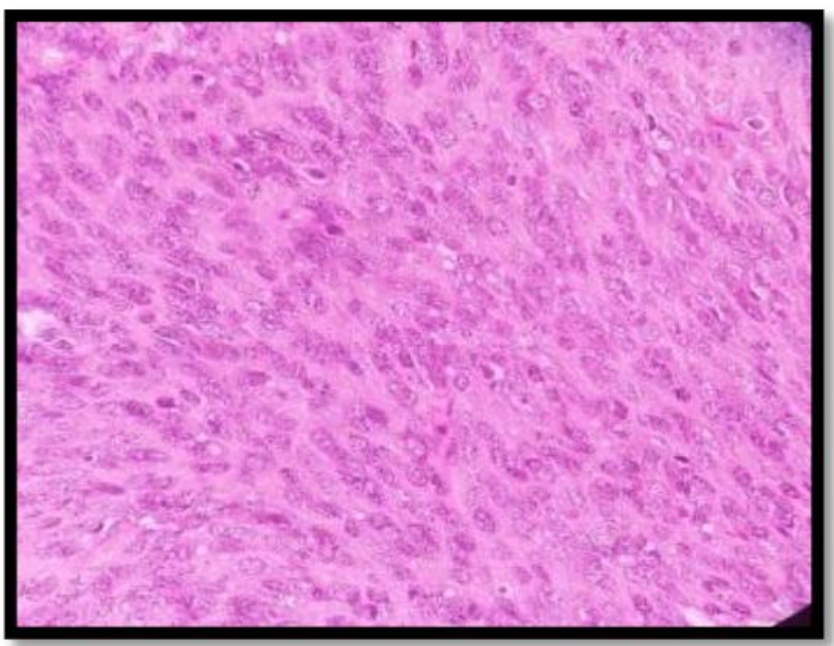

(G) EPITHELOID CELLS (40 X) 


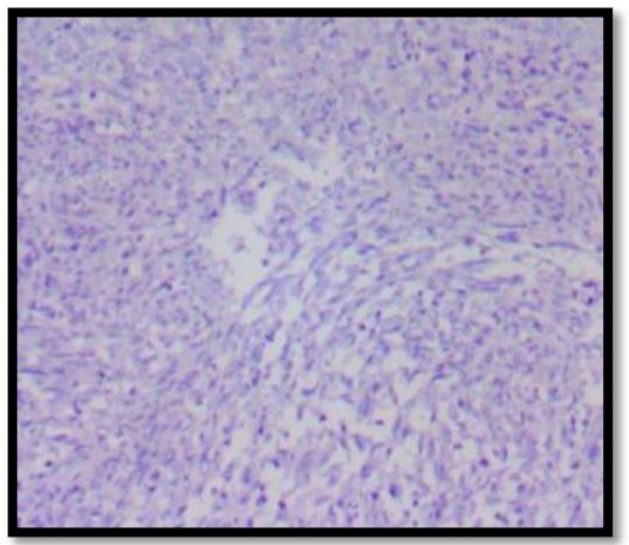

ERG

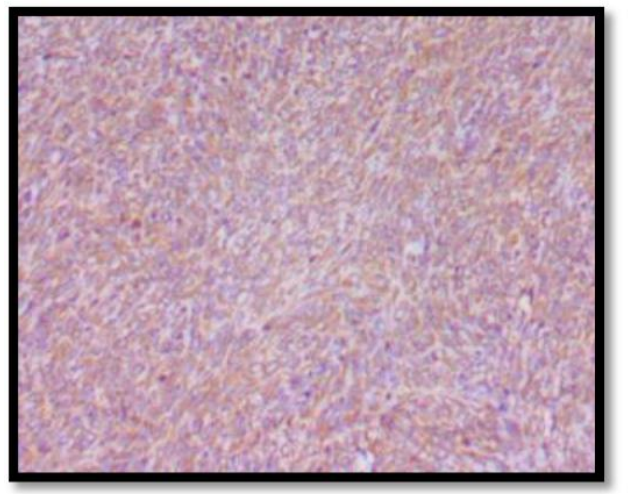

VIMENTIN

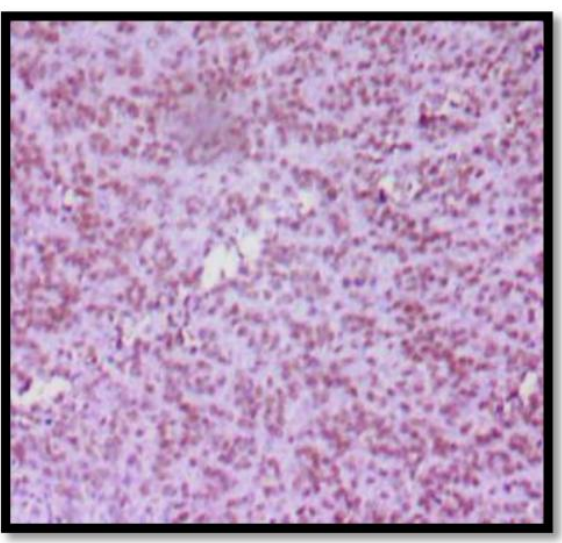

FLI-1

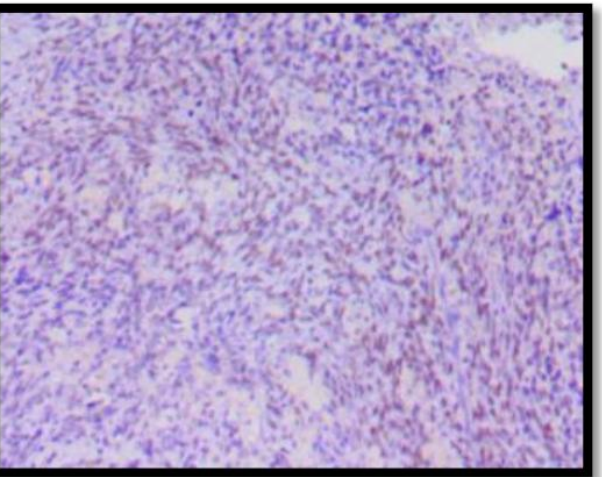

TLE-1

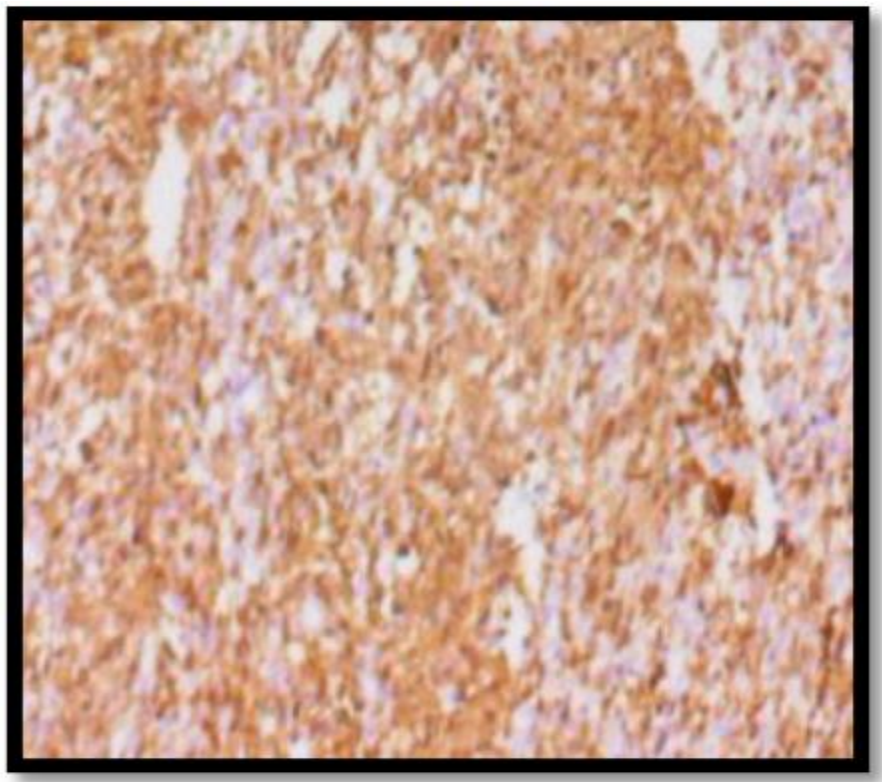

\section{S-100}

\section{DISCUSSION}

Synovial sarcomas are malignant, high-grade, soft-tissue neoplasms that are estimated to represent between $5 \%$ and $10 \%$ of all soft-tissue sarcomas. In fact, in adults, synovial sarcoma is the fourth most common type of sarcoma after malignant fibrous histiocytoma, liposarcoma and rhabdomyosarcoma [5, 6].

This tumor is most prevalent in adolescents and adults between 15 and 40 years age [6, 7]. Concerning gender incidence, the male: female ratio is $1.2: 1$, with males being more frequently affected. 
Primary site distribution are Extremities: $68.7 \%$, Trunk: $15.7 \%$, Head and neck: $6.3 \%$, Intrathoracic: $5.3 \%$, Intra-abdominal: $1.8 \%$, Other: $2.2 \%$.

Translocation commonly seen are (Gold standard to diagnose synovial sarcoma)

- SS18-SSX1: 60 - 70\% monophasic, 30 - $40 \%$ biphasic

- SS18-SSX2: 97\% monophasic, 3\% biphasic

- SS18-SSX1 inhibits Snail gene while SS18SSX2 inhibits Slug gene [9].

Histologically, synovial sarcoma is typically characterized by epithelium-like and/or spindle cell components arranged in a biphasic or monophasic pattern, although a poorly differentiated variant has also been described recently [8]. The biphasic pattern is considered the "classic" type and is generally recognizable by the coexistence of morphologically different but genetically similar epithelial cells and fibroblast-like spindle cells [5]. The monophasic type is closely related to the biphasic type and represents merely one extreme of its morphological spectrum, sharing phenotypical features identical to the spindlecell portion or the epithelium-like component, corresponding to the monophasic fibrous variant or to the monophasic epithelial variant, respectively $[5,6]$. Histologically, the poorly differentiated type is composed mostly of small, solidly packed, oval or spindle-shaped cells that seem to have an intermediate phenotype between epithelial and spindle cells, often with scant differentiation, simulating other neoplasms, namely, angiosarcoma or small-cell carcinoma.

Synovial sarcomas not only are locally aggressive but also have a higher metastatic potential than most other soft-tissue sarcomas. Hence, the overall prognosis for synovial sarcoma patients is poor. In fact, according to most reports, notwithstanding intensive multimodal therapy, including surgery, chemotherapy and radiotherapy, the outcomes of these patients have changed little in the past two decades $[8,10]$.

In our case Fine needle aspiration showed spindle shaped nucleus with few wavy nucleus with moderate pleomorphism so a spindle cell neoplasm was considered. The epithelioid cells were not evident in FNAC. On further histopathology examination it showed both epithelioid cells and spindle cells with vague storiform pattern so epithelioid sarcoma and biphasic synovial sarcoma were considered also seen were areas with sinusoidal spaces lined by malignant cells filled with RBC's seen so angiosarcoma was considered. Also seen were foamy cells with mild atypia admixed with pleomorphic spindle cells so undifferentiated pleomorphic sarcoma was considered as differential diagnosis. Special stains like PAS was not done.
On IHC examination

ERG negative- Vascular tumor ruled out.

FLI-1 Weakly positive- MPNST ruled out.

TLE-1 Strongly positive - Synovial sarcoma considered.

S-100 Positive - Neuronal differentiation considered.

Finally the Patient was diagnosed as Biphasic synovial sarcoma with neuronal differentiation with metastasis. Metastasis was not confirmed histologically.

\section{SPECIAL STAINING}

Secretions in the epithelial cells, intracellular clefts and pseudoglandular spaces stain positively with the Periodic acid -Schiff (PAS), colloidal iron, Alcian blue and mucicarmine stains.

Second type of mucinous material, stromal or mesenchymal mucin which is elaborated by the spindle cells also stains positively for colloidal iron and alcian blue stains, but it is weakly carminophilic and stains negatively with the PAS preparation.

\section{IMMUNOHISTOCHEMISTRY \\ Positive stains}

- TLE1 (Transducin-like enhancer of split 1): It is involved in modulating differentiation through several pathways, including inhibition of the Wnt / beta catenin signaling cascade. $80-90 \%$, relatively specific and sensitive marker, but new studies are finding more tumors with TLE1 positivity.

- Cytokeratin's: $\sim 90 \%$, variable positivity depending on the keratin polypeptide and the component

$>$ Epithelial component is consistently positive for CK7, CK8, CK14, CK18, CK19 and variable for CK17 (77\%), CK13 (25\%), CK6 (24\%) and CK16 (23\%)

$>$ Spindle cell component usually focal and variably positive for CK7 (79\%), CK19 (60\%), CK18 (46\%), CK8 ( 45\%), CK14 (28\%), CK17 (10\%), CK20 (6\%)

- EMA: 29 - 90\%, variable and focal, generally less than cytokeratin's.

- BCL2: 79 - 100\%.

- S100: $40 \%$ of cases with neuronal differentiation.

- NY-ESO-1: 76\% strong and diffuse staining.

- SYT( Synovial sarcoma translocation) : 87\%, strong nuclear staining, may lack specificity.

\section{CONCLUSION}

On FNAC it was suspected to be a neuronal tumor and on further histopathological examination angiosarcoma, epithelioid sarcoma, synovial sarcoma were considered as differential diagnosis and on IHC examination it turned out to be a synovial sarcoma with neuronal differentiation. Since the tumor has poor prognosis the diagnosis must not be delayed. Awareness of this tumor by the surgeons and pathologists can 
hasten diagnosis, and this in turn can potentially increase survival of the patient. Therefore, a high index of suspicion for this disease should be kept in mind, particularly when evaluating young people, as this is the most commonly affected group. However ancillary studies like Immunohistochemistry, cytogenetics are needed for definitive diagnosis and molecular study remains the gold standard.

\section{REFERENCES}

1. Fisher C. Synovial sarcoma. Ann Diagn Pathol. 1998;2:401-421.

2. Weiss SW, Goldblum JR. Enzinger, Weiss's Soft Tissue Tumors. 4th Ed. St Louis, MO: CV Mosby; 2001.

3. Ghadially FN. Is synovial sarcoma a carcinosarcoma of connective tissue? Ultrastruct Pathol. 1987;11:147-151.

4. Smith ME, Fisher C, Wilkinson LS, Edwards JC. Synovial sarcoma lack synovial Differentiation. Histopathology. 1995;26:279-281.

5. Siegel HJ, Sessions W, Casillas MA Jr, Said-AlNaief N, Lander PH, Lopez-Ben R. Synovial sarcoma: clinicopathologic features, treatment, and prognosis. Orthopedics. 2007, 30:1020-1027.
6. Weitz J, Antonescu CR, Brennan MF. Localized extremity soft tissue sarcoma: improved Knowledge with unchanged survival over time. J Clin Oncol. 2003, 21:2719-2725.

7. Sultan I, Rodriguez-Galindo C, Saab R, Yasir S, Casanova M, Ferrari A: Comparing Children and adults with synovial sarcoma in the Surveillance, Epidemiology, and End Results program, 1983 to 2005: an analysis of 1268 patients. Cancer. 2009, 115:3537-3547

8. Ferrari A, Gronchi A, Casanova M, Meazza C, Gandola L, Collini P, Lozza L, Bertulli R, Olmi P, Casali PG. Synovial sarcoma: a retrospective analysis of 271 patients of all ages Treated at a single institution. Cancer. 2004, 101:627-634.

9. Saito T. The SYT-SSX fusion protein and histological epithelial differentiation in synovial Sarcoma: relationship with extracellular matrix remodeling. Int $\mathrm{J}$ Clin Exp Pathol. 2013;6(11):2272-2279.

10. Shi W, Indelicato DJ, Morris CG, Scarborough MT, Gibbs CP, Zlotecki RA. Long-term Treatment outcomes for patients with synovial sarcoma: a 40-year experience at the University of Florida. Am J Clin Oncol. 2012. 